\section{AB0741 PSORIATIC ARTHRITIS QUALITY OF LIFE QUESTIONNAIRE: TRANSLATION, CULTURAL ADAPTATION AND VALIDATION INTO PORTUGUESE LANGUAGE}

A. Barcelos ${ }^{1}$, C. Ambrósio ${ }^{1}$, J. da Silva ${ }^{2,3}$, S. McKenna ${ }^{4}$, J. Wilburn ${ }^{4}$ P.L. Ferreira ${ }^{5,6},{ }^{1}$ Rheumatology Department, Centro Hospitalar Baixo Vouga, Aveiro; ${ }^{2}$ Rheumatology Department, CHUC; ${ }^{3}$ Faculdade de Medicina, Universidade de Coimbra, Coimbra, Portugal; ${ }^{4}$ Galen Research, Manchester, United Kingdom; ${ }^{5}$ Faculdade Economia, Universidade de Coimbra; ${ }^{6}$ Centro de Estudos e Investigação em Saúde, Faculdade Economia - Universidade de Coimbra, Coimbra, Portugal

Background: Psoriatic Arthritis (PsA) has a strong negative impact in the quality of life of patients, through pain, stiffness, functional disability, deformity and a variety of other dimensions. The Psoriatic Arthritis Quality of Life (PsAQoL) questionnaire is a disease-specific instrument developed to measure quality of life in patients with PsA.

Objectives: The aims of this study were to culturally adapt the questionnaire for Portugal, and evaluate its reliability and validity in patients with PsA.

Methods: The original UK English version of PsAQoL was translated into Portuguese by a bilingual translation panel. An independent lay panel reviewed the instrument's item phrasing to ensure appropriateness in colloquial European Portuguese. Structured cognitive debriefing interviews were conducted with ten PsA patients to assess the acceptability, the understanding and the redundancy or ambiguity of the questionnaire. The Portuguese PsAQoL was subsequently applied to PsA patients followed at the Rheumatology Department of Centro Hospitalar do Baixo Vouga, E.P.E. To assess reproducibility, thirty patients with PsA completed the Portuguese PsAQoL on two occasions, two weeks apart. A larger sample was recruited to determine internal consistency and construct validity. Descriptive statistical analysis was used to characterize the data. The Nottingham Health Profile (NHP) was used as a comparator instrument.

Results: Translation and adaptation were successful. The validation sample included 104 patients, $67 \%$ of whom were men. Their median age was 50.2 $(\mathrm{SD}=12.1)$ years and most were married. Cronbach's alpha for the Portuguese version of the PsAQoL was 0.91 and the test-retest reliability was 0.92 , indicating that the measure has good internal consistency and produces low random measurement error. The PsAQoL could distinguish between groups of patients defined by self-reported general health status, self-reported severity of PsA and flare of arthritis. Duration of arthritis did not influence PsAQoL scores. There was a positive correlation between the total score of APsQoL and each of the dimensions of the NHP.

Conclusions: The Portuguese version on the PsAQoL was found to be relevant, understandable and easy to complete, reliable and valid. It should be considered for use in clinical practice and research settings to asses PsA-specific QoL.

\section{References:}

[1] McKenna S, Doward LC, Whalley D, et al. Development of the PsAQoL: a quality of life instrument specific to psoriatic arthritis. Ann Rheum Dis 2014; 63(2): 162-169.

[2] Wink F, Arends S, McKenna S, et al. Validity and reliability of the Dutch adaptation of the Psoriatic Arthritis Quality of Life (PsAQoL) Questionnaire. PloS One 2013; 8(2): e55912.

[3] Billing E, McKenna S, Staun M \& Lindqvist U. Adaptation of the Psoriatic Arthritis Quality of Life (PsAQoL) instrument for Sweden. Scand J Rheumatol 2010; 39: 223-228.

Disclosure of Interest: None declared

DOI: 10.1136/annrheumdis-2017-eular.3297

\section{AB0742 ULTRASONOGRAPHY OF THE NAIL UNIT IN PSORIASIS AND PSORIATIC ARTHRITIS: A QUALITATIVE AND QUANTITATIVE ANALYSIS}

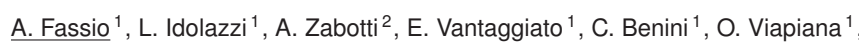
M. Rossini ${ }^{1}$, D. Gatti ${ }^{1} .{ }^{1}$ Rheumatology, Aoui Verona Reumatologia, Verona; ${ }^{2}$ Rheumatology, University Hospital "Santa Maria della Misericordia", Udine, Italy

Background: the nail unit is a shared topic of interest both for dermatologist and rheumatologist [1]. It is easy to study using imaging techniques such as ultrasonography. The nail was considered one of the possible target of assessment for the disease, especially when ultrasonography is performed. Ultrasound imaging of nails is a quite new technique, available since high frequencies probes were introduced in musculoskeletal examination and nail was considered one of the possible target for assessing the disease and defining its prognosis $[2,3]$.

Objectives: to evaluate the presence of the nail involvement and subclinical alterations using ultrasonography in psoriasis and psoriatic arthritis.

Methods: the study sample included 82 patients affected by psoriasis and/or psoriatic arthritis and 50 healthy controls $(\mathrm{HC})$. The patients were consecutively enrolled during their routine visit in the outpatient clinic and they performed clinical and ultrasonographic evaluation of the nail. Activity indexes (DAPSA, PASI, NAPSI) and other clinimetric parameters were considered.

Results: multivariate analysis of variance (mANOVA) was performed between groups and the nail plate and nail bed thickness, PASI, NAPSI, age and BMI were considered (table 1). Post hoc analysis underlined the differences between groups, in particular between healthy and affected. The lesions for nail plate and nail bed in the PASI score were analyzed using Pearson's chi square test and,
Table 1. patient groups and ANOVA results

\begin{tabular}{lccc}
\hline & $\mathrm{HC}$ & $\mathrm{PSOs}$ & $\mathrm{PsAs})$ \\
& $\mathrm{N}=50(\mathrm{M} / \mathrm{F} 22 / 28)$ & $\mathrm{N}=31(\mathrm{M} / \mathrm{F} 22 / 9)$ & $\mathrm{N}=51(\mathrm{M} / \mathrm{F} 26 / 25)$ \\
\hline & Mean $\pm \mathrm{SD}$ & Mean $\pm \mathrm{SD}$ & Mean $\pm \mathrm{SD}$ \\
Eta & $48.44 \pm 13.95$ & $48.22 \pm 14.7$ & $50.92 \pm 13.9$ \\
BMl & $24.61 \pm 3.92$ & $28.61 \pm 4.95^{\star}$ & $28.64 \pm 5.84^{\star}$ \\
Thickness NAIL PLATE & $0.051 \pm 0.006$ & $0.063 \pm 0.011^{\star}$ & $0.065 \pm 0.014^{+}$ \\
Thickness NAIL BED & $0.22 \pm 0.02$ & $0.25 \pm 0.05^{\star}$ & $0.25 \pm 0.04^{\star}$ \\
\hline
\end{tabular}

secondary, odd ratios for significant results were calculated. Nail plate thickness and nail bed thickness were correlated with PASI, NAPSI, BMI and DAPSA. ROC curves were calculated obtaining also quantitative cut offs for nail plate and nail bed thickness in the affected vs healthy ones.

Conclusions: the application of ultrasonography is of potential advantages supported by the data of this study and strengthens the information available in literature, also adding quantitative parameters for the ultrasonography of the nail. References:

[1] Ash ZR, Tinazzi I, Gallego CC, et al. Psoriasis patients with nail disease have a greater magnitude of underlying systemic subclinical enthesopathy than those with normal nails. Ann Rheum Dis 2012;71:553-6. doi: 10.1136/ annrheumdis-2011-200478.

[2] Raposo I, Torres T. Nail psoriasis as a predictor of the development of psoriatic arthritis. Actas Dermo-Sifiliográficas Engl Ed 2015;106:452-7. doi: 10.1016/ j.adengl.2015.02.001.

[3] Gutierrez M, Filippucci E, De Angelis R, et al. A sonographic spectrum of psoriatic arthritis: "the five targets." Clin Rheumatol 2010;29:133-42. doi: 10. 1007/s10067-009-1292-y.

Disclosure of Interest: None declared

DOI: 10.1136/annrheumdis-2017-eular.2723

\section{AB0743 LOW RATES OF MAJOR ADVERSE CARDIAC EVENTS, MALIGNANCIES, AND SERIOUS INFECTIONS IN PATIENTS WITH PSORIASIS AND PSORIATIC ARTHRITIS TREATED WITH APREMILAST FOR $\geq 156$ WEEKS: POOLED ANALYSIS FROM THE ESTEEM AND PALACE 1-3 PHASE 3 TRIALS}

A. Kavanaugh ${ }^{1}$, M. Augustin ${ }^{2}$, E. Lespessailles ${ }^{3}$, K.A. Papp ${ }^{4}$, M. Paris ${ }^{5}$, R. Chen ${ }^{5}$, D.D. Gladman ${ }^{6}$, D.M. Pariser ${ }^{7}$, K. Peris ${ }^{8} .{ }^{1}$ University of California, San Diego, School of Medicine, la Jolla, United States; ${ }^{2}$ Institute for Health Care Research in Dermatology and Nursing (IVDP), University Medical Center Hamburg-Eppendorf, Hamburg, Germany; ${ }^{3}$ University of Orléans, Orléans, France; ${ }^{4}$ Probity Medical Research, Waterloo, Canada; ${ }^{5}$ Celgene Corporation, Summit, United States; ${ }^{6}$ Toronto Western Hospital, Toronto, Canada; ${ }^{7}$ Eastern Virginia Medical School and Virginia Clinical Research, Inc., Norfolk, United States: ${ }^{8}$ Catholic University of Rome, Rome, Italy

Background: Apremilast (APR), an oral PDE4 inhibitor, was effective in phase 3 randomized, placebo (PBO)-controlled trials assessing treatment of moderate to severe plaque psoriasis (ESTEEM 1 and 2) and psoriatic arthritis (PSA; PALACE $1-3)$.

Objectives: We report incidence of MACE, malignancies, and serious infections (Sls; opportunistic and non-opportunistic) in pts receiving APR $30 \mathrm{mg}$ BID (APR30) for $>156$ wks in a pooled analysis of these studies.

Methods: Incidence rates and exposure-adjusted incidence rates (EAIR)/100 pt-yrs of MACE, malignancies, SIs, and serious opportunistic infections (SOIs) are reported for 0 to $16 \mathrm{wks}, 0$ to $\leq 52 \mathrm{wks}$, and the APR-exposure period ( 0 to $\geq 156 \mathrm{wks}$ ) for pts receiving APR30 any time during the studies, through February $2015 ; \sim 30 \%(n=575)$ of pts received $>3 \mathrm{yrs}$ ( $>156 \mathrm{wks})$ of APR exposure.

Results: 2,242 pts were included in the safety analysis for 0 to 16 wks (PBO $n=913$, pt-yrs exposure $[p y]=260.2 ;$ APR30 $n=1,329$, py=377.8); 1,905 pts received APR30 during the APR-exposure period, representing 3,527.5 py; exposure during 0 to $\leq 52$ wks was $1,524.5$ py. At baseline $64.2 \%$ of PsA pts (PALACE 1-3) in the APR30 group were receiving concomitant DMARDs (including methotrexate). Incidence of MACE with APR30 was low and comparable to PBO during 0 to 16 wks. During 0 to $\leq 52$ wks and the APR-exposure period, incidence of MACE (EAIR/100 pt-yrs) remained low (Table). Incidence rates (EAIR/100 pt-yrs) of hematologic malignancies, non-melanoma skin cancers, and solid tumors were similar with PBO $(0.0,1.2,0.4)$ and APR30 $(0.0,1.3,0.3)$ during 0 to 16 wks; incidence rates remained low during 0 to $\leq 52$ wks and the APR-exposure period (Table). During 0 to $16 \mathrm{wks}$, the overall rate of infections (serious and non-serious) was low and comparable between pts receiving PBO (20.6\%) and APR30 (24.8\%). The overall rate of infections (serious and non-serious) was $42 \%$ during 0 to $\leq 52$ wks and comparable to rates during the PBO-controlled period ( 0 to $16 \mathrm{wks}$ ); the majority of reported infections (URTI, nasopharyngitis, sinusitis) were not serious. During the PBO-controlled period (0 to 16 wks), rates of SIs with APR30 were low and comparable to PBO; no SOls were reported. During 0 to $\leq 52$ wks, the overall rate of Sls was low $(0.6 \%$; EAIR/100 pt-yrs: 0.7$)$. The rate of SIs remained low (1.8\%; EAIR/100 pt-yrs: 1.0) during the long-term cumulative APR-exposure period ( 0 to $\geq 156$ wks) (Table). No clustering of any particular event was noted with respect to SIs; most events occurred in only 1 pt. No clinical reactivation of tuberculosis was reported with long-term APR30 exposure (0 to $\geq 156$ wks). The rate of marked hematologic abnormalities remained low with long-term APR exposure. 


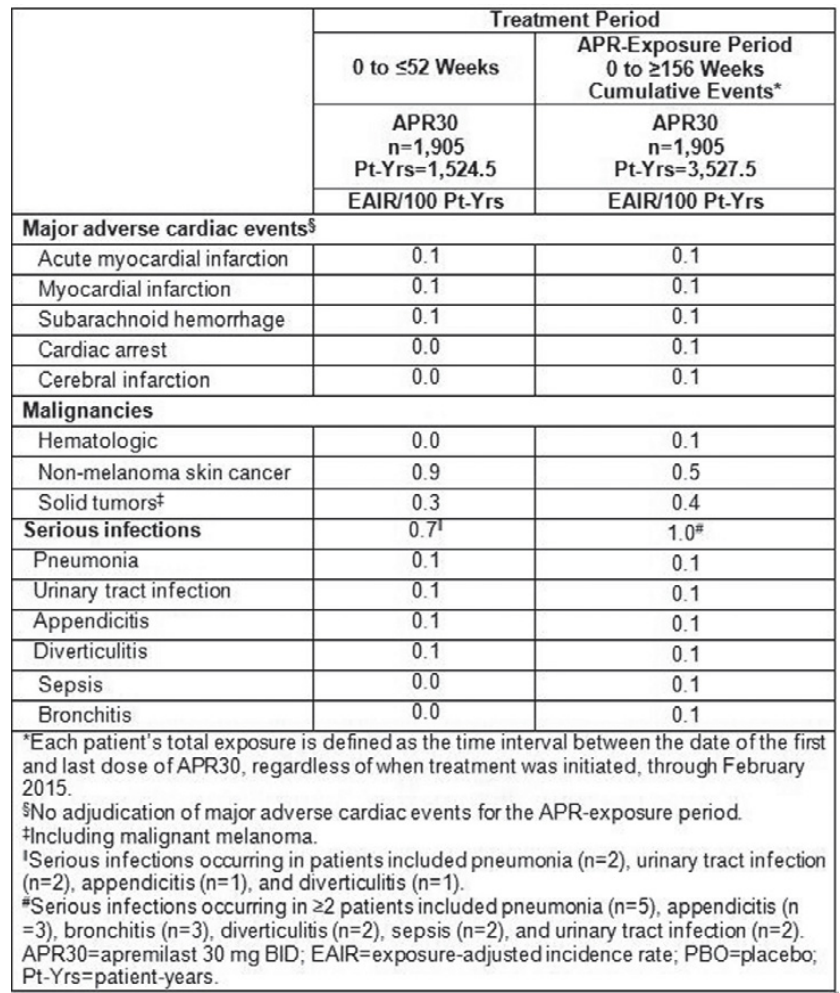

Conclusions: Incidence of MACE, malignancies, and SIs was low in pts with psoriasis and PsA receiving APR30 for $\geq 156$ wks. No new safety signals or SOls were observed over time with APR30.

Disclosure of Interest: A. Kavanaugh Grant/research support from: Abbott, Amgen, AstraZeneca, BMS, Celgene Corporation, Centocor-Janssen, Pfizer, Roche, and UCB, M. Augustin Consultant for: AbbVie, Almirall, Amgen, Biogen, Boehringer Ingelheim, Celgene Corporation, Centocor, Eli Lilly, GSK, JanssenCilag, LEO Pharma, Medac, Merck, MSD, Novartis, Pfizer, UCB, and XenoPort, Speakers bureau: AbbVie, Almirall, Amgen, Biogen, Boehringer Ingelheim, Celgene Corporation, Centocor, Eli Lilly, GSK, Janssen-Cilag, LEO Pharma, Medac, Merck, MSD, Novartis, Pfizer, UCB, and XenoPort, E. Lespessailles Grant/research support from: Amgen, Celgene Corporation, Eli Lilly, and Novartis, Speakers bureau: Amgen, Celgene Corporation, Eli Lilly, and Novartis, K. Papp Grant/research support from: AbbVie, Allergan, Amgen, Anacor, Astellas, Baxalta, Biogen-Idec, Boehringer Ingelheim, Bristol-Myers Squibb, Celgene Corporation, Dermira, Dow Pharma, Eli Lilly, Galderma, Genentech, Glenmark, GSK, Janssen, Kyowa Hakko Kirin, LEO Pharma, Medlmmune, Merck, Merck Serono, Mylan, Novartis, Pfizer, Regeneron, Roche, Sanofi-Aventis, Stiefel, Takeda, UCB, and Valeant, Consultant for: AbbVie, Akros, Allergan, Amgen, Anacor, Astellas, AstraZeneca, Baxalta, Baxter, Biogen-Idec, Boehringer Ingelheim, Bristol-Myers Squibb, Can-Fite BioPharma, Celgene Corporation, Celtic, Cipher, Dermira, Dow Pharma, Eli Lilly, Formycon, Forward Pharma, Funxional Therapeutics, Galderma, Genentech, Genexion, Glenmark, GSK, Janssen, Kyowa Hakko Kirin, LEO Pharma, Lypanosys, Medlmmune, Merck, Merck Serono, Mitsubishi Pharma, Mylan, Novartis, Novommune, Pan Genetics, Pfizer, Regeneron, Roche, SanofiAventis, Stiefel, Sun Pharma, Takeda, UCB, Valeant, Vertex, and Xoma, M. Paris Employee of: Celgene Corporation, R. Chen Employee of: Celgene Corporation, D. Gladman Grant/research support from: AbbVie, Amgen, BMS, Celgene Corporation, Janssen, Novartis, Pfizer, and UCB, Consultant for: AbbVie, Amgen, BMS, Celgene Corporation, Janssen, Novartis, Pfizer, and UCB, D. Pariser Grant/research support from: Abbott Laboratories, Amgen, Astellas Pharma US, Asubio Pharmaceuticals, Basilea Pharmaceutical, Celgene Corporation, Dow Pharmaceutical Sciences, Eli Lilly, Galderma Laboratories, Graceway Pharmaceuticals, Intendis, Johnson \& Johnson, Novartis Pharmaceuticals, Novo Nordisk A/S, Ortho Dermatologics, Photocure ASA, Stiefel Laboratories, and Valeant Pharmaceuticals, K. Peris Consultant for: Eli Lilly, LEO Pharma, MEDA, and Roche

DOI: 10.1136/annrheumdis-2017-eular.5065

\section{AB0744 DOES TIMING OF INITIATION OF ANTI-TNF AGENTS AFFECT THE QUALITY OF LIFE OUTCOMES IN PATIENTS WITH PSORIASIS AND PSORIATIC ARTHRITIS?}

P.W. Barnes ${ }^{1}$, N. Rich-Garg ${ }^{2}$, D. Choi ${ }^{3}$, A. Deodhar ${ }^{2} .{ }^{1}$ School of Medicine; ${ }^{2}$ Division of Arthritis \& Rheumatic Diseases; ${ }^{3}$ Public Health \& Preventative Medicine, Oregon Health and Science University, Portland, United States

Background: Psoriatic Arthritis (PsA) affects up to $30 \%$ of people with psoriasis ${ }^{1}$.
While Tumor Necrosis Factor inhibitors (TNFi) are effective agents for PsA, the relationship between early treatment and patient reported outcomes in a real world setting has not been reported previously.

Objectives: To assess whether timely treatment with TNFi leads to better improvement in quality of life outcomes than delayed treatment.

Methods: This was a retrospective analysis of patients with PsA and/or Psoriasis (PsO) using TNFi with or without methotrexate, and who had a minimum of 2 visits at the Center of Excellence for Psoriasis and Psoriatic Arthritis at our university. Detailed demographic and clinical characteristics of this cohort have been published previously ${ }^{2}$. Demographics, quality of life measures (e.g. Routine Assessment of Patient Index Data - RAPID3, Psoriasis Quality of Life - PQoL12, Short Form 12 - SF-12), and clinical data (percent of body surface area involved with $\mathrm{PsO}-\mathrm{BSA} \%$ ) were collected from patient-reported questionnaires and electronic medical records. Only those patients who had a chronological overlap of treatment exposure and QoL measures such as RAPID3, BSA, SF12 and PQOL were included. To ascertain treatment effects, a mixed-effects model was fitted to estimate the trend of each QoL outcome of a patient separately. Then, for all estimated trends of an outcome, a linear regression model was employed to explore the association between the magnitude of estimated trends and timeliness of TNFi treatments.

Results: The quality of life measures were not affected by how early after the disease onset TNFi treatment was started (in other words, no statistically significant associations between the effectiveness of TNFi treatment and disease duration) for RAPID3 ( $\mathrm{p}=0.285), \mathrm{SF}-12(\mathrm{p}=0.674)$, or $\mathrm{BSA}(\mathrm{p}=0.078)$. For PQoL, there was a significant association between the trend of treatment effects and timeliness of treatment. A day of delay into treatment was resulted in a reduction of $4.4 \times 10^{-4} /$ day in the trend of PQoL scores $(p=0.007)$.

Conclusions: In this sample of PsA \& PsO patients, timing of starting TNFi in patients with PsA had significant impact on improvements in the PQoL but not other quality of life measures such as RAPID3, SF-12 and BSA. A relatively short treatment history might have led to the negative correlations.

References:

[1] McLaughlin M, et.al. Early treatment of psoriatic arthritis improves prognosis. Practitioner 2014258 (1777) 21-24.

[2] Truong B et.al. Demographics, clinical disease characteristics and quality of life in a large cohost of psoriasis patients with and without psoriatic arthritis. Clin, Cosm and Inv Dermatology 2015: 8: 563-569.

Disclosure of Interest: None declared

DOI: 10.1136/annrheumdis-2017-eular.1535

\section{AB0745 SUBCLINICAL ATHEROSCLEROSIS EVOLUTION IN PSORIATIC ARTHRITIS PATIENTS TREATED WITH ANTI-TNF ALPHA: 5 YEARS FOLLOW UP}

A. Ortolan ${ }^{1}$, M. Puato ${ }^{2}$, G. Boschetti ${ }^{3}$, M. Lorenzin ${ }^{1}$, A. Hoxha ${ }^{1}$, L. Punzi ${ }^{1}$ R. Ramonda ${ }^{1} .{ }^{1}$ Rheumatology Unit, Department of Medicine DIMED, University of Padova; ${ }^{2}$ Clinica Medica III, Department of Medicine DIMED, Universityof Padova; ${ }^{3}$ Clinica Medica III, Department of Medicine DIMED, University of Padova, Padova, Italy

Background: Psoriatic arthritis (PsA) is associated with increased morbility and mortality and an accelerated atherosclerosis. Influence of anti-TNFalpha treatment (a widely used therapy in PsA) in subclinical atherosclerosis is still unclear.

Objectives: The aim of this study was to evaluate subclinical atherosclerosis progression before, during and after 5 years of anti-TNFalpha treatment.

Methods: Twenty-seven consecutive PsA patients were evaluated before TNF blockers therapy (T0), after 2 years (T1) and after 5 years (T2) of treatment. Subclinical atherosclerosis was evaluated through carotid duplex scanning, analyzing intima-media thickness (IMT) and flow-mediated dilation (FMD). IMT values were expressed as IMT mean (cumulative mean of all the IMT mean in every analyzed carotid segment) and M-MAX (cumulative mean of all the higher IMT in every analyzed carotid segment). Response to therapy was studied by the evaluation of tender and swollen joints (Tj and Sj), DAS 28 (disease activity score), erythrocyte sedimentation rate (ESR) and C-reactive protein (CRP). Metrologic and metabolic data were collected. For the statistical evaluation of parameters over time (T0 vs T1, T1 vs T2) Student's T test for paired data was used Results: From T0 to T1 a deterioration in IMT-mean and M-MAX $(p<0.01)$ was

Table

\begin{tabular}{|l|l|l|l|}
\hline & T0 & T1 & T2 \\
\hline IMT-mean & $0.72 \pm 0.15$ & $0.91 \pm 0.37^{*}$ & $0.92 \pm 0.34$ \\
\hline M-MAX & $0.89 \pm 0.18$ & $1.06 \pm 0.39^{*}$ & $1.10 \pm 0.35^{* *}$ \\
\hline FMD & $5.40 \pm 1.93$ & $5.37 \pm 1.66$ & $5.40 \pm 1.89$ \\
\hline Tender joints (n) & $8.10 \pm 5.56$ & $2.09 \pm 2.32^{*}$ & $1.72 \pm 2.05$ \\
\hline Swollen joints (n) & $3.85 \pm 3.84$ & $0.25 \pm 0.72^{*}$ & $0.50 \pm 0.92$ \\
\hline CRP & $11.25 \pm 9.16$ & $2.91 \pm 1.72^{*}$ & $2.73 \pm 2.51$ \\
\hline DAS28 & $4,16 \pm 0.67$ & $2.30 \pm 0.82^{*}$ & $2.40 \pm 0,9$ \\
\hline
\end{tabular}

Legend: IMT= intima-media thickness; $\mathrm{M}-\mathrm{MAX}=$ cumulative mean of all the higher IMT in every analyzed carotid segment; $\mathrm{FMD}=$ flow-mediated dilation; $\mathrm{CRP}=\mathrm{C}$ Reactive Protein; DAS28=Disease Activity Score $28 j$ joints; ${ }^{*}=p<0.01$ with respect to the previous determination; ${ }^{* *}=\mathrm{p}<0.05$ with respect to the previous determination 